\author{
M. Vuichyk, L. Rashkovets'kyi, S. Lavoryk, P. Lytvyn, K. Svezhentsova
}

\title{
Forming of CdZnTe Thin Films Grown by Hot Wall Epitaxy and their Properties
}

\author{
V.Ye. Lashkaryov Institute of Semiconductor Physics NAS of Ukraine, Kyiv, Ukraine, vuychik@kiev.ua
}

In this work morphological, X-ray structural and optical studies of CdZnTe films grown by hot wall epitaxy method at relatively low substrate temperatures were performed. Possible mechanisms and processes of self-organization that occur during the growth of such structures are considered. It is shown that at thickness of film more than $130 \mathrm{~nm}$ on the surface, large (lateral size $150-200 \mathrm{~nm}$, height - up to $10 \mathrm{~nm}$ ) and small crystals are observed. The thicknesses and energy of the band gap width of the CdZnTe films grown at different growth times were determined. It is shown that the film absorption edge in the transmission spectra depends on the film thickness and the reasons for the shift of the film absorption edge are discussed.

Keywords: CdZnTe, hot wall epitaxy, morphology, self-organization.

Received 24 May 2021; Accepted 5 October 2021.

\section{Introduction}

Thin films of cadmium telluride and CdZnTe solid solution based on it are widely used in the creation of solar cells [1-2], as well as devices in the infrared (IR) and terahertz (THz) range [3, 4 and references]. CdZnTe, in contrast to CdTe, differs in the presence of $\mathrm{Zn}$ ions, which improves its mechanical properties (increase microhardness) and enhances the bond covalence. In addition, the content of $4 \%$ zinc leads to a perfect match of the lattice parameters with the material CdHgTe.

Using CdZnTe thin films requires knowledge of the factors influencing the processes of nucleation and formation of such structures. This is necessary to control the self-organization of such systems. Depending on the size, shape, composition, ordering and functionality of such semiconductor nanocrystals, it is possible to change the electronic and optical properties of structures with great accuracy. Considering all these characteristics gives rise to a new generation of nano- and microstructured materials with high innovative potential and determines the further process in technology [5-6].

Despite the fact that the application of thin semiconductor films based on CdZnTe and the study of their growth began in the last century, the problem of creating a high-quality semiconductor film with predetermined parameters still remains relevant $[4,5]$. In the works of Dr. Freik's school [see e.g. 6] studied the mechanisms of initiation and growth of CdTe thin-film structures. The aim of our work is to develop nanocomposite materials based on CdZnTe semiconductors and to study the processes of initiation and self-organization in $\mathrm{CdZnTe}$ films grown on silicon substrates and fresh cleaved surface $\mathrm{BaF}_{2}$ substrates by hot wall epitaxy (HWE) method at relatively low substrate temperatures $\left(\sim 100{ }^{\circ} \mathrm{C}\right)$ by $\mathrm{X}$-ray diffraction analysis and optical transmission within range the CdZnTe band gap.

The choice of CdZnTe material and technological growth parameters is due to the fact that to simulate its application on the epitaxial layer $\mathrm{CdHgTe}$ as a protective passivating coating in the manufacture of IR and $\mathrm{THz}$ radiation receivers. Since the optimal thickness of the passivating layer is a necessary condition for the effective operation of the sensitive element, so to solve this problem, the influence of growth time on the growth 
of thin films was studied. The growth temperature of the films was such as to take into account the temperature constraints that exist in $\mathrm{CdHgTe}$ semiconductors. At high temperatures $(\mathrm{T}>140 \mathrm{~K})$ in this material there are irreversible structural transformations that lead to the destruction of the ternary solid solution, primarily due to the release of mercury atoms from the crystal lattice.

\section{Experimental details}

CdZnTe films were grown by hot wall epitaxy method on silicon substrates and fresh cleaved surface $\mathrm{BaF}_{2}$ substrates at relatively low substrate temperatures $\left(\sim 100{ }^{\circ} \mathrm{C}\right)$. The hot wall epitaxy method [7] is a quasiequilibrium method in which achieves the greatest approximation to the stoichiometric composition in the vapor phase, and this process is accompanied by minimal material loss. At the same time there is an intensive exchange interaction of a thin semiconductor film grown from the vapor phase. The requirement of homogeneity of properties of films, and also maintenance of economy of use of spraying installations impose strict conditions on characteristics of evaporators. It is often necessary for the evaporator to provide a constant film deposition rate regardless of the amount of material remaining in the reactor. Fulfillment of this condition eliminates the effect of changing the spray rate during each process on the structure of the film. The reactor is also required to provide a molecular flow distribution that achieves maximum uniformity of coating thickness over a larger area. The thickness of the film anywhere in the substrate should be as uniform as possible. The growth process began with the location of the holder with the substrate above the reactor, and ended with the diversion. The pressure of residual gases in the vacuum chamber was created by forvacuum and diffusion pumps with a nitrogen trap and was not worse than $2.6 \cdot 10^{-5} \mathrm{~Pa}$ and controlled by a BMT- 8 vacuum gauge, the temperatures of the walls, sources and substrate were controlled by built-in thermocouples.

The surface morphology of the grown structures was studied on an atomic force microscope (AFM) Nanoscope IIIa Dimention 3000 (Digital Instruments, USA) in the periodic contact mode. Measurements were performed in the central zone of the sample using serial

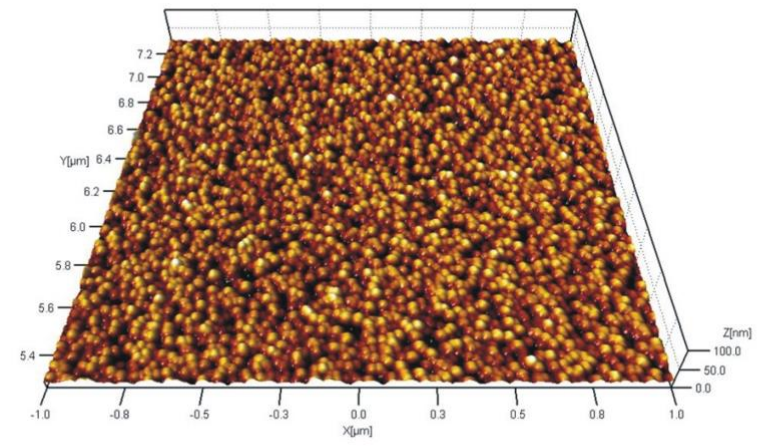

a silicon probes NSG-11 with a nominal radius of curvature of the tip up to $10 \mathrm{~nm}$ (NT-MDT, Russia). The phase composition of $\mathrm{CdZnTe}$ thin films grown on single-crystal silicon substrates was studied by $\mathrm{X}$-ray diffraction on the DRON-4-07 device $(\mathrm{Cu} \mathrm{K \alpha}$ radiation is average, irradiation wavelength is $1.5418 \AA$ ). Registration was carried out in the range of 2 Theta 10 50 degrees with a step of 0.05 .

Optical studies (transmission and reflection) were performed on a two-beam Shimadzu UV-3600 spectrophotometer at room temperature. The resolution of the devices was not worse than $0.1 \mathrm{~nm}$. For comparison, the reflection and transmission spectra of the substrates on which the films were grown were also recorded.

The thickness of the deposited CdZnTe films was carried out using the Micron-Alpha interferometer. Micron-alpha allows to reset a microtopography of a surface in real time with accuracy on a vertical 5 nanometer. Measurement is doing by means of handling of interference pictures sequence logged by the digital videocamera, with computer control of drifting of a support mirror.

\section{Results and discussion}

In vFig. 1 - Fig. 2 shows the surface morphology of CdZnTe thin films by HWE method on single-crystal silicon substrates at relatively low substrate temperatures $\left(\sim 100{ }^{\circ} \mathrm{C}\right)$. The wall temperature in these experiments was the same and was $400{ }^{\circ} \mathrm{C}$. The temperature of the evaporation source was the same and was $380^{\circ} \mathrm{C}$. The variable in these experiments was the growth time of CdZnTe. So for the thin film CdZnTe, the surface morphology of which is shown in Fig. 1.a, growth time was $1 \mathrm{~min}$. As can be seen from the figure, the film has a fine-grained shape [8]. The grain, in this case, has a size of $150-250 \mathrm{~nm}$ at the base, and a height of $30-40 \mathrm{~nm}$.

With increasing growth time to 5 minutes (the morphology of the surface of this sample is not shown) the nature of the film does not change, but increase both the lateral size of the grains and their height. In this case, the grain height increases to $50 \mathrm{~nm}$. The nature of the film changes with increasing growth time of the thin semiconductor film to $10 \mathrm{~min}$ (Fig. 1,b). At the same

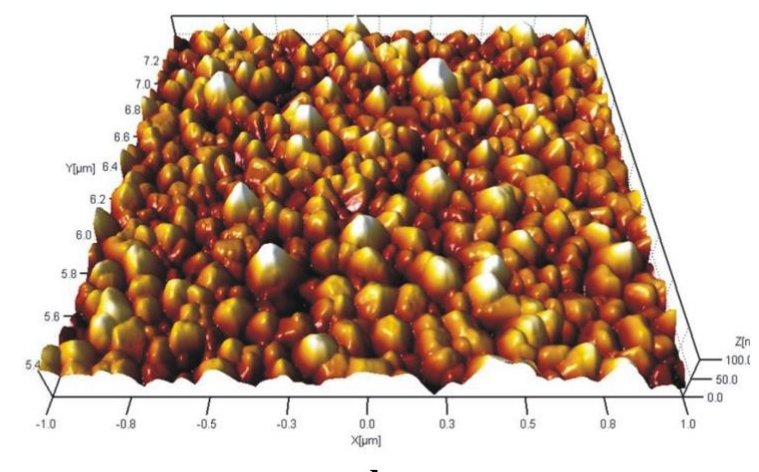

b

Fig. 1. Morphology of the surface of the CdZnTe thin film grown by HWE method. Growth times were 1 minute (a) and 10 minutes (b) 


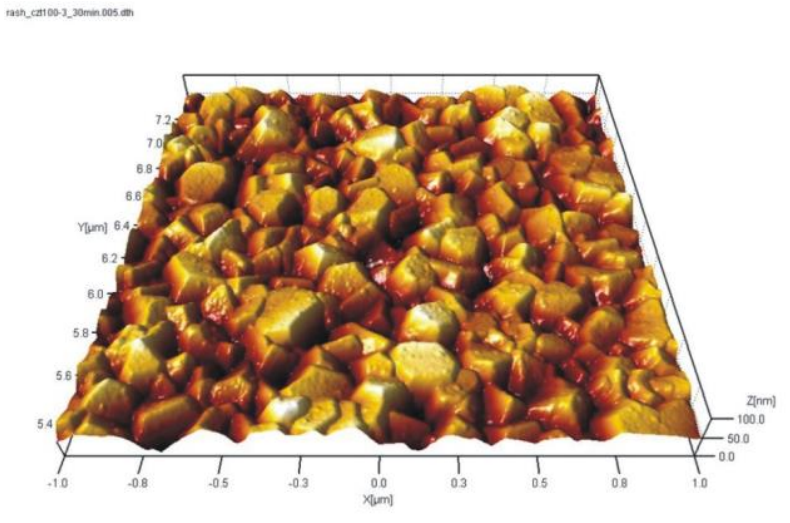

a

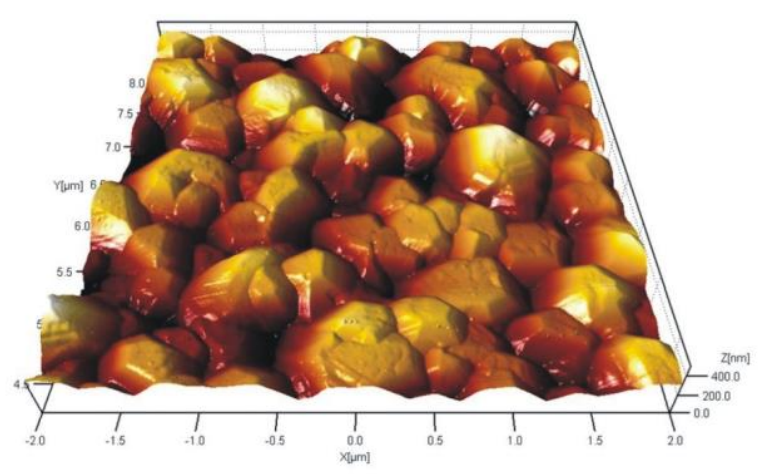

$\mathrm{b}$

Fig. 2. Morphology of the surface of the CdZnTe thin film grown by hot wall epitaxy method. Growth times were 30 minutes (a) and 120 minutes (b).

time both lateral sizes of crystallites, and height continue to grow. However, both large crystallites (lateral dimensions 150 - $200 \mathrm{~nm}$, height up to $10 \mathrm{~nm}$ ) and small ones are observed on the surface.

To understand the reasons for the formation of such CdZnTe crystallites on the surface of the substrate, consider the peculiarities of the origin of films from the initial physical principles. An essential feature of the formation of a new phase on the surface of the substrates in comparison with the homogeneous formation in the volume is that the substrate contains various defects. It is known that defects are divided into point and linear, which include chips, dislocations and scratches. Even an ideal substrate has defects such as Tamm levels formed by incomplete crystal planes. Existing theories of the formation of a new phase on the surface of solids are based either on the classical theory of nucleation [9], modified for the two-dimensional case and taking into account the role of defects in the nucleation process, or on the atomic Walton-Rodin model [10]. The first stage of condensation of films is adsorption. When condensing from a one-component vapor, monomolecular and dissociative adsorption are most often distinguished, which at small numbers of substrate filling lead to uniform appearance of adatoms over the entire unoccupied surface of the substrate with some constant velocity. The adsorbed atoms can either be desorbed back into vapors or jump to one of the neighboring nodes (diffuse). After the equilibrium between the surface and the initial phase is established, a two-dimensional "gas" of adatoms with a surface density is formed on the surface of the substrate, which depends on a number of parameters.

In order for a new phase to condense from the supersaturated vapor phase in the metastable state, it is necessary that the fluctuations of free energy, which leads to overcoming the activation barrier, be positive. The presence of such a barrier is due to the fact that the free energy of formation of a new phase from supersaturated vapor has a maximum at some point, which is called critical. In the case of multicomponent films, the free nucleation energy depends on the number of particles of each component. It should be noted that very often various substrate defects initiate nucleation, reducing the height of the activation barrier. So the steps of the chips can significantly increase the rate of film formation. The activation barrier of nucleation at the cleavage stage can be so small (of the order of $k T$ ) that the nucleus of two particles already becomes supercritical. In this case, the new phase will be formed not due to normal nucleation, but due to spinoidal decay, ie due to increasing periodic fluctuations in the concentration of the substance. The distribution of the islands of the new phase on the chipping step by size and their spatial distribution will be different.

Thus, after the appearance on the surface of the substrate, the nuclei of the new phase begin to grow, interacting with the atoms of the old phase from which they were formed. This phase can be a single- or multicomponent vapor, a single- or multicomponent melt solution, an amorphous phase, a solid solution, etc., depending on this, the growth mechanisms of the islands also differ significantly. In our case, it is a multicomponent vapor, and the individual components of which have different vapor pressures. In the case of the vapor phase, the embryos grow due to the diffusion flux of atoms of the old phase to their surface. It should be noted that the surface introduces significant differences in the mechanisms of growth compared to the growth in the volume of solids. On the surface, there are the following main methods of atomic migration and energy distribution, including heat energy: three-dimensional or three-dimensional diffusion of atoms and threedimensional heat dissipation; two-dimensional diffusion of atoms on the substrate surface and two-dimensional heat dissipation; one-dimensional diffusion of atoms along the substrate steps, dislocation outlets and other linear defects. The islands can also grow due to the direct flow of atoms from the vapor to their surface. After the atom has crossed the interfacial boundary, it joins the surface of the island. The surface of the island, like the surface of any crystal, can be rough, atomically smooth and vicinal. Depending on which of the surfaces the island has, the process of attaching atoms to it will be different [11]. Rough at the atomic level interphase surfaces grow by the mechanism of normal growth, atomically smooth - due to the nucleation of twodimensional nucleus of a crystal on their faces, vicinal surfaces - due to either the movement of existing steps, or helical dislocations coming to the surface. The next 
step is to insert the adatom into the island of the new phase. Depending on which of the processes is limit, the growth rate significantly depends. It should be noted that with increasing growth time to 30 minutes (see Fig. 2.a), the nature of the morphology of the film surface changes dramatically. The islands begin to coalesce and both small and large crystallites are observed on the surface, approximately the same height as in the previous case (Fig. 1,b), but with even larger lateral dimensions. This process of coalesce is even better seen in Fig. 2.b, where the growth time of the film was 2 hours.

Let us now discuss the peculiarities of the growth of multicomponent islands, which are represented by our CdZnTe islands. Multicomponent systems can be divided into two groups. One includes systems whose islands are solid solutions, and the other includes systems with islands consisting of stoichiometric compounds. In the process of growth of thin multicomponent films, atoms fall on the surface of the substrate, from which islands of various chemical compounds can be formed. Some (sometimes most) of the islands of these compounds are an intermediate phase in the growth of other phases. The islands of any chemical compound will be called the phase s. As in single-component systems, the growth of multicomponent islands occurs due to the same mechanisms of mass transfer. However, there is one significant difference, which is that the chemical components that make up the island of phase $\mathrm{s}$ can diffuse to it in different ways. One of the components can get to the surface of the island due to surface diffusion, and the other - due to diffusion in the gas phase. In addition, the boundary stages of these components may differ. In this situation, it is usually necessary to find the component that limits the process, and to determine the main flow of matter to the island.

In the case of the growth of islands from multicomponent solutions, their growth rate is determined by the intensity of the supply of matter and the intensity of heat removal from their surface. In this case, matter and heat can be supplied and removed in completely different ways.

Thus, the mechanism of growth of the islands determines the rate of their growth, which is part of the basic equation of the kinetics of condensation of films and, thus, ultimately determines the structure and composition of the grown film.

The late stage of growth of thin films is characterized by the fact that in it begins the interaction of the islands of the new phase, which originated earlier. There are three types of cluster interaction: 1) merging of clusters due to their migration on the surface, 2) merger of clusters due to their lateral growth, 3) the growth of large clusters due to the evaporation of small (the socalled stage Ostwald ripening).

The latter type of interaction is carried out through a generalized diffusion or temperature field. In our case (see Fig. 2.a - Fig. 2.b), the interaction of the islands, which leads to coalesce of clusters is observed at a time of growth of a thin film of 30 minutes. However, it should be noted that the growth time is not decisive for coalesce of clusters.

Diffractograms of the samples are shown in Fig. 3.

The phase composition of CdZnTe samples grown at the same temperature and different growth time corresponds to cadmium telluride. As the film thickness decreases, there is a decrease in the intensity of CdTe reflexes, an increase in the relative intensity of the amorphous halo with a maximum in the region 2 Theta $=$ $20^{\circ}$ and a peak with a maximum at 2 Theta $=33.2^{\circ}$, which corresponds to the line (002) of single-crystal silicon (substrate). A reflex corresponding to the crystalline phase of ZnTe appears in the diffractogram of a CdZnTe film with a growth time of $1 \mathrm{~min}$. The obtained results are consistent with the results obtained in [12].

To obtain information about the optical properties of $\mathrm{CdZnTe}$ thin films the transmission and reflection spectra

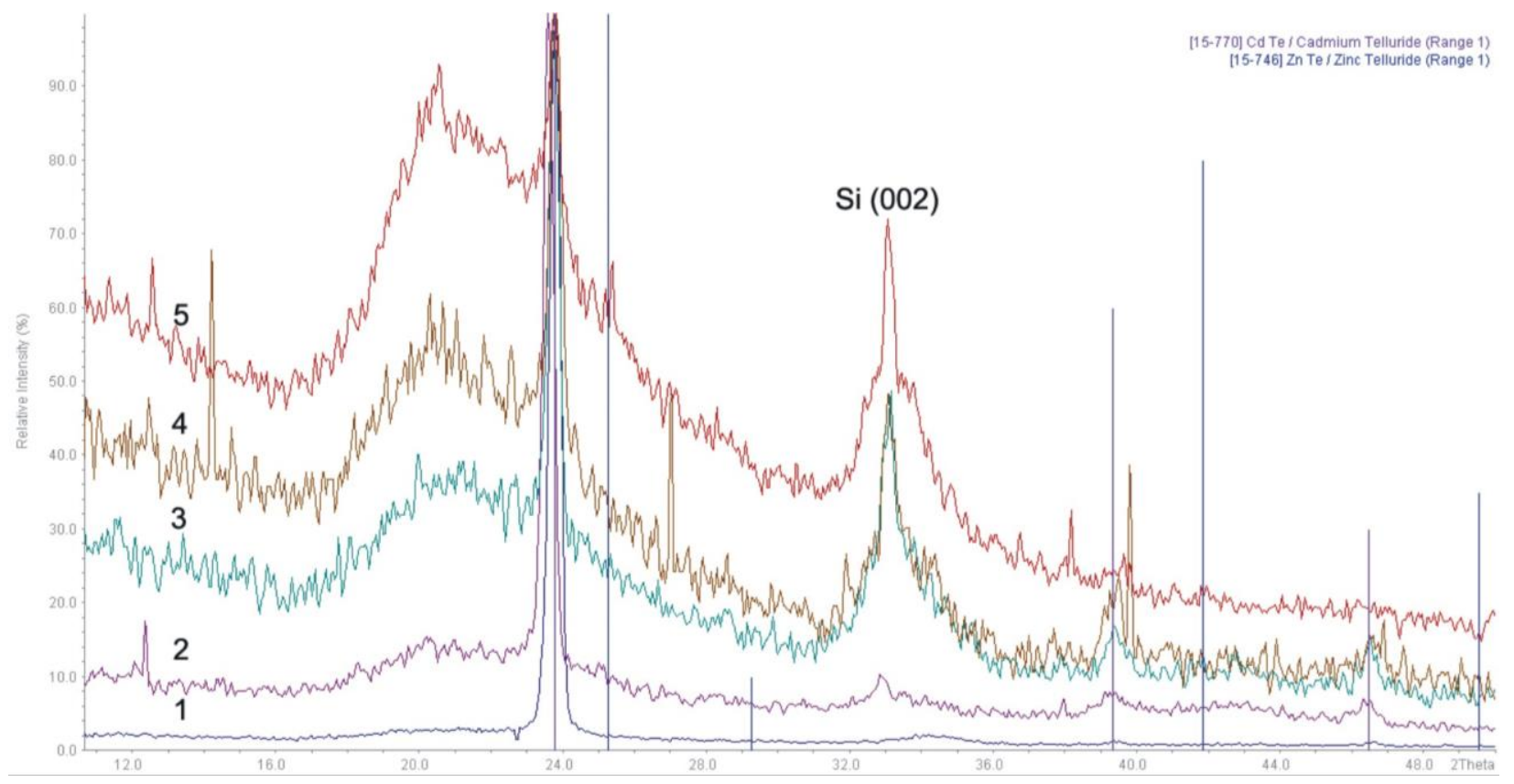

Fig. 3. Diffractograms of CdZnTe thin films, which were grown by the HWE method on silicon substrates at the same temperature and different growth times: (1) - 120 min., (2) - 30 min., (3) - 10 min., (4) - 5 min., (5) - 1 min. 
Thickness and band gap of $\mathrm{CdZnTe}$ thin films grown on $\mathrm{BaF}_{2}$ substrates at different growth times

\begin{tabular}{|c|c|c|c|c|}
\hline Sample & $\begin{array}{c}\mathrm{T}_{\text {sub }}, \\
{ }^{\circ} \mathrm{C}\end{array}$ & Time of grown, min. & $\begin{array}{c}\text { Thickness, } \\
\mathrm{nm}\end{array}$ & $\begin{array}{c}\mathrm{E}_{\mathrm{g},} \\
\mathrm{eV}\end{array}$ \\
\hline CZT100_12 & 100 & 60 & 810 & 1.54 \\
\hline CZT100_32 & 100 & 30 & 380 & 1.63 \\
\hline CZT100_42 & 100 & 10 & 130 & 2.08 \\
\hline CZT100_52 & 100 & 5 & 70 & - \\
\hline
\end{tabular}

in the region of the fundamental edge of the absorption of the film material were investigated. All optical studies (transmission and reflection (not shown)) were performed on a two-beam spectrophotometer Shimadzu UV-3600 at room temperature.

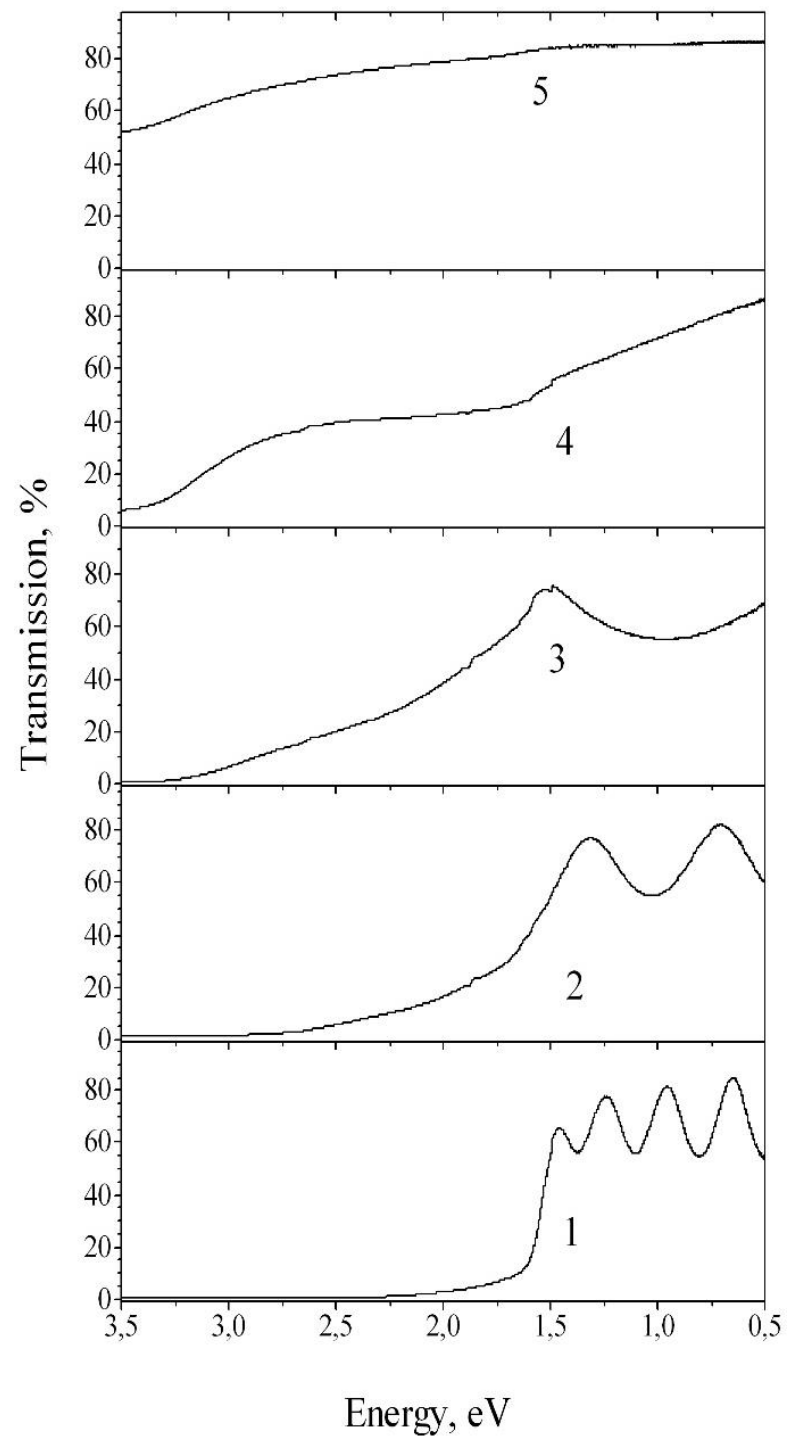

Fig. 4. Transmission spectra of CdZnTe thin films grown on fresh cleaved surface $\mathrm{BaF}_{2}$ substrates at different growth times: 1 - 60 min., 2 - 30 min., 3 - 10 min., 4 - 5 min., 5 - 1 min.

The reflection spectra repeat the characteristic reflection pattern of the substrate up to $1000 \mathrm{~nm}$ and differ after the edge of the fundamental optical absorption. It should be noted that the reflection coefficient of the film is slightly less than the reflection coefficient of the substrate.

To study the transmission spectra in the region of the fundamental absorption edge (Fig. 4), thin CdZnTe films were grown on fresh cleaved $\mathrm{BaF}_{2}$ substrates. Temperatures and growth times were the same as for growing CdZnTe films on single-crystal silicon substrates.

From the transmission spectra of CdZnTe thin films on $\mathrm{BaF}_{2}$, it is seen that at a short application time the spectrum of the film is close to the transmission spectrum of the substrate. As the film thickness increases, the absorption edge shift can be observed. This shift can be due to several reasons. As is known, in solid solutions the position of the absorption edge is determined by the content of components - in our case the position of the absorption edge strongly depends on the zinc content in the CdZnTe semiconductor film. Other reasons for the shift of the absorption edge are the presence of mechanical stresses arising from the mismatch of the parameters of the crystal lattices of the film and the substrate; and the influence of quantum-dimensional effects affecting the energy system of the thin film, as well as the presence of an amorphous phase in the film.

The value of the band gap $\mathrm{E}_{\mathrm{g}}$ can be estimated using the assumption of straight-band transitions between the valence band and the conduction band $[1,13]$.

The calculated values of the band gap and the determined thicknesses of CdZnTe thin films are given in Table 1. As can be seen from the table, the band gap of the film decreases with increasing film thickness and approaches the value of single-crystal CdZnTe.

The value of $E_{\mathrm{g}}$ films applied in 1 and 5 minutes are atypical, so at such thicknesses this method of determining $\mathrm{E}_{\mathrm{g}}$ cannot be used.

\section{Conclusions}

In this work the growth of the films by hot wall epitaxy method at relatively low temperature of the substrates are studied. Morphological, X-ray structural and optical studies of these films were demonstrated. It is shown that the film thickness is more than $130 \mathrm{~nm}$, large and small crystallites on the surface are observed and their interaction leads to the fusion of crystallites at the time of growth of the thin film more 30 minutes. As the 
film thickness decreases, the intensity of CdTe reflexes decreases and the relative intensity of the amorphous halo increases. The value of the band gap $\mathrm{E}_{\mathrm{g}}$ of thin films is estimated and the reasons for the shift of the absorption edge of the films are discussed.
Vuichyk M. - Ph.D, senior researcher;

Rashkovets'kyi L. - researcher;

Lavoryk S. - Ph.D, senior researcher;

Lytvyn P. - Ph.D, senior researcher;

Svezhentsova K. - Ph.D, senior researcher.

[1] Jiaying Bie, Shilin Wang, Yongsheng Guan, Xiang Zhang, Yan Sun, Changhong Sun, Ke Tang, Jian Huang, Meng Cao, Jun Ling, Ke Tan, Yue Shen, Linjun Wang, Energy Fuels 35(9), 8234 (2021); https://doi.org/10.1021/acs.energyfuels.1c00356.

[2] E. Camacho-Espinosa, A. Lopez-Sanchez, I. Rimmaudo, R. Mis-Fernandez, J.L. Pena, Solar Energy 193,31 (2019); https://doi.org/10.1016/j.solener.2019.09.023.

[3] W. Lei, J. Antoszewski, L. Faraone, Appl. Phys. Rev. 2, 041303 (2015); https://doi.org/10.1063/1.4936577.

[4] F. Sizov, M. Vuichyk, K. Svezhentsova, Z. Tsybrii, S. Stariy, M. Smolii, Material Science in Semiconductor Processing 124, 105577 (2021); https://doi.org/10.1016/j.mssp.2020.105577.

[5] B.J. Kim, J.F. Wang, G. MLalev, Y.-G. Park, D. Shindo, M. Isshiki, Materials Chemistry and Physics 80(3), 581 (2003); https://doi.org/10.1016/S0254-0584(02)00387-5.

[6] Y.P. Saliy, L.I. Nykyruy, R.S. Yavorskyi, S.Adamiak. Journal of nano- and electronic physics 9(5), 05016 (2017). https://doi.org/10.21272/jnep.9(5).05016..

[7] A. Lopez-Otero, Thin solid films 49(1), 3 (1978); https://doi.org/10.1016/0040-6090(78)90309-7.

[8] I.V. Kurilo, H.A. Ilchuk, S.V. Lukashuk, I.O. Rudyi, V.O. Ukrainets, N.V. Chekaylo, Semiconductors 45, 1531 (2011); https://doi.org/10.1134/S1063782611120086.

[9] J.P. Hirth and G.M. Pound, Condensation and Evaporation: Nucleation and Growth Kinetics (Hardcover, Pergamon Press, 1963).

[10] D. Walton, J. Chem. Phys. 37, 2182 (1962); https://doi.org/10.1063/1.1732985.

[11] S.A. Kukushkin, V.V. Slezov, Dispersnyye sistemy na poverkhnosti tverdykh tel (S-Pb, Nauka, 1996) (in russ.)

[12] V. Kosyak, Y. Znamenshchykov, A. Čerškus, Yu P. Gnatenko, L. Grase, J. Vecstaudza, A. Medvids, A. Opanasyuk, G. Mezinskis, 682, 543 (2016); https://doi.org/10.1016/j.jallcom.2016.05.065.

[13] R. Petrus, H. Ilchuk, A. Kashuba, I. Semkiv, E. Zmiiovska, Funct. Mater. 27(2), 342 (2020); https://doi.org/10.15407/fm27.02.342.

М.В. Вуйчик, Л.В. Рашковецький, С.Р. Лаворик, П.М. Литвин, К.В. Свеженцова

\title{
Формування тонких плівок CdZnTe при вирощуванні методом «гарячої стінки» та їх властивості
}

\author{
Інститут фізики напівпровідників ім. В.С.Лашкарьова НАН України, Київ, Украӥна, vиусhik@kіеv.иа
}

\begin{abstract}
В даній роботі проведено морфологічні, рентгено-структурні та оптичні дослідження плівок $\mathrm{CdZnTe}$ вирощених методом молекулярної епітаксії «гаряча стінка», при відносно низьких температурах підкладки. Розглянуто можливі механізми та процеси самоорганізації, що відбуваються при рості таких структур. Показано, що при товщині плівки більше 130 нм, на поверхні спостерігаються великі (латеральні розміри 150 - 200 нм, висота - до 10 нм) і маленькі кристаліти. Визначено товщини та енергія ширини забороненої зони плівок CdZnTe, вирощених при різному часі росту. Показано, що край поглинання плівок у спектрах пропускання залежить від товщини плівки та обговорено причини зсуву краю поглинання плівок у спектрах пропускання.
\end{abstract}

Ключові слова: CdZnTe, молекулярна епітаксія «гаряча стінка», морфологія, самоорганізація. 